\title{
ANODIC FORMATION AND SEM CHARACTERIZATION OF ZIRCONIUM OXIDE NANOSTRUCTURED FILMS
}

\author{
Kirill KAMNEV, Jan PRASEK, Alexander MOZALEV \\ CEITEC - Central European Institute of Technology, Brno University of Technology, Brno, Czech Republic, EU \\ kirill.kamnev@ceitec.vutbr.cz, alexander.mozalev@ceitec.vutbr.cz
}

https://doi.org/10.37904/nanocon.2019.8711

\begin{abstract}
Zirconium oxide $\left(\mathrm{ZrO}_{2}\right)$ is a widely utilized inorganic material with excellent dielectric, optical, and biocompatible characteristics. The properties and areas of the $\mathrm{ZrO}_{2}$ applications can be further broadened by making the material nanostructured. In this work, anodic $\mathrm{ZrO}_{2}$ nanostructured films were developed and characterized by scanning electron microscopy. The films were prepared by anodizing magnetron-sputtered $\mathrm{Al} / \mathrm{Zr}$ bilayers in two regimes: galvanostatic/potentiostatic anodizing in $(\mathrm{COOH})_{2}$ and $\mathrm{H}_{2} \mathrm{SO}_{4}$ solutions (anodized films) and that followed by the high-speed reanodizing to a significantly higher anodic voltage (reanodized films). The growth of a porous anodic alumina (PAA) layer followed by PAA-assisted oxidation of the $\mathrm{Zr}$ underlayer was achieved. The anodized films consist of arrays of self-organized spatially ordered $\mathrm{ZrO}_{2}$ nanohillocks while the reanodized films comprise arrays of vertically aligned $\mathrm{ZrO}_{2}$ nanorods. The growth of amorphous $\mathrm{ZrO}_{2}$ nanohillocks and nanorods within the alumina pores via migration of $\mathrm{Zr}^{4+}$ cations is a unique situation for anodic films on zirconium, which normally grow crystalline and by $\mathrm{O}^{2-}$ anion transport at the oxide/metal interface only. The achievement is a milestone towards understanding the ion transport during the PAA-assisted anodization of valve metals with low cation transport numbers
\end{abstract}

Keywords: Anodizing, zirconium oxide, porous anodic alumina, nanostructure, electron microscopy

\section{INTRODUCTION}

Zirconium oxide $\left(\mathrm{ZrO}_{2}\right)$ is a multifunctional inorganic compound highly utilized in many technological areas due to its remarkable properties such as high melting point, good mechanical and thermal resistance, chemical stability, low electrical conductivity, and biocompatibility. It has been employed in protective coatings, optoelectronic devices, sensors, fuel cells, catalysts, and medical implants [1-5].

Active steps have been made to further enhance the properties of the oxide through making it nanostructured. Commonly used methods include sol-gel and variety of gas-phase processes [6,7]. Relatively recently, an electrochemical approach (anodizing) has been developed as a simple and versatile technique for forming $\mathrm{ZrO}_{2}$ nanoporous films on top of the metal [8]. However, preparation of substrate-supported 1-D $\mathrm{ZrO}_{2}$ structures like nanoneedles, nanorods, and nanowires remains a challenge. Most recently, an alternative anodization technique has emerged for processing superimposed valve-metal films consisting of a layer of aluminum over a layer of different metal. The aluminum layer is first converted to porous anodic alumina (PAA), then the underlying metal is anodized through the alumina nanopores. Although the approach was a success for forming $\mathrm{Ta}, \mathrm{Nb}, \mathrm{W}$, and $\mathrm{Hf}$ oxide nanostructures [9-11], the obstacles for growing zirconium-oxide nanostructures are the noticeably low $\mathrm{Zr}^{4+}$ cation transport number $(0.05)$ and the crystallization of the oxide under the high electric field $[12,13]$.

Here we report the formation of self-ordered and uniformly aligned $\mathrm{ZrO}_{2}$ nanostructures via the PAA-assisted anodizing of $\mathrm{Al} / \mathrm{Zr}$ bilayers on substrates. Due to the appropriate electrolytic and electrical conditions, a sustainable growth of nanostructured zirconium anodic oxide was achieved not only at the oxide/metal interface but also at the electrolyte/oxide interface, i.e. within the alumina nanopores. The films were examined by high-resolution scanning electron microscopy after selective dissolution of the PAA overlayer. 


\section{EXPERIMENTAL}

\subsection{Sample preparation}

A face-side polished $\mathrm{Si}$ wafer, covered with a $300 \mathrm{~nm}$ layer of $\mathrm{SiO}_{2}$, was used as a starting substrate. A layer of $\mathrm{Zr}, 150 \mathrm{~nm}$ thick, followed by a layer of $\mathrm{Al}, 700 \mathrm{~nm}$ thick, were deposited on the substrate via magnetron sputtering from $\mathrm{Zr}$ and $\mathrm{Al}$ targets of respectively $99.95 \%$ and $99.999 \%$ purity. Anodization experiments were carried out in aqueous solutions of $0.2 \mathrm{M}(\mathrm{COOH})_{2}, 0.6 \mathrm{M}(\mathrm{COOH})_{2}, 0.4 \mathrm{M} \mathrm{H}_{2} \mathrm{SO}_{4}$, and $2 \mathrm{M} \mathrm{H}_{2} \mathrm{SO}_{4}$ at room temperature. For the first series of samples (anodized films) anodic process was performed in a constant current mode followed by a potentiostatic mode after the complete consumption of the aluminum layer. The second series of samples (reanodized films) were prepared by anodizing at the same conditions followed by a rapid rise in the applied voltage to a significantly higher value (reanodizing), in order to promote the growth of zirconium oxide within the PAA pores. After the anodizing and reanodizing, the samples were thoroughly rinsed with deionized water and dried in an oven at $120^{\circ} \mathrm{C}$ for 10 minutes. In order to selectively dissolve the PAA overlayer (PAA-free films), the samples were dipped in a stirred solution of $0.45 \mathrm{M} \mathrm{H}_{3} \mathrm{PO}_{4}$ and $0.2 \mathrm{M} \mathrm{Cr}_{2} \mathrm{O}_{3}$ heated to $65^{\circ} \mathrm{C}$, thoroughly washed in deionized water, and dried in air at $120^{\circ} \mathrm{C}$ for 10 minutes.

\subsection{Sample characterization}

The surface morphology and cross fractures of the PAA-free samples were examined in a TESCAN MIRA II field-emission scanning electron microscope, equipped with an InBeam detector for secondary electrons, without depositing any conducting layer.

\section{RESULTS AND DISCUSSION}

\subsection{Anodizing behavior}

A typical electrochemical response during anodizing, followed by reanodizing in $0.2 \mathrm{M}(\mathrm{COOH})_{2}$ is shown in Figure 1. The first processing stage is the same for both the anodized and reanodized samples. When a constant current density of $10 \mathrm{~mA} \cdot \mathrm{cm}^{-2}$ is applied, the voltage begins to gradually increase at a rate of about $1.7 \mathrm{~V} \cdot \mathrm{s}^{-1}$ due to the growth of a compact anodic film on the Al layer. After reaching a maximum of about $61 \mathrm{~V}$, the voltage begins to gradually decrease until it attains a steady-state value of approximately $50 \mathrm{~V}$ at the end of stage I. Such voltage behavior reflects the nucleation and growth of a porous anodic film. At the commencement of stage II, a steady-state PAA growth begins, then the voltage remains stable. After about 90 seconds of the stable PAA growth, the aluminum layer is almost fully consumed and the bottoms of growing PAA cells reach the $\mathrm{Zr}$ metal (the end of stage II). Then the voltage is allowed to slightly grow up to a set point of $55 \mathrm{~V}$, after that the setup is automatically switches to a potentiostatic mode, preventing the oxide from further growth. In about $60 \mathrm{~s}$ of voltage stabilization, the current density decreases to an almost steady low value. The voltage-time behavior during the anodic process is typical for PAA growth, so one could expect a good degree of pore self-ordering in the upper PAA layer [14].

During stage III, a different approach is implemented for forming the reanodized samples (Figure 1). After a 60 -second current decay after beginning of stage III, the voltage is rapidly raised at a rate of $10 \mathrm{~V} \cdot \mathrm{s}^{-1}$ (sweep rate) to $250 \mathrm{~V}$ (reanodizing voltage) and is stabilized for $120 \mathrm{~s}$. During the voltage sweep, the current density increases rapidly to a value of about $9 \mathrm{~mA} \cdot \mathrm{cm}^{-2}$ and remain relatively stable until the voltage reaches the set point.

During the voltage stabilization period at stage III, the current drops to an almost steady and substantially low value, then the polarization is cut off. The electrochemical responses for anodizing and reanodizing other samples in all the solutions correlated with the behavior shown in Figure 1, the exact process variables and morphological features being collected in Table 1. 


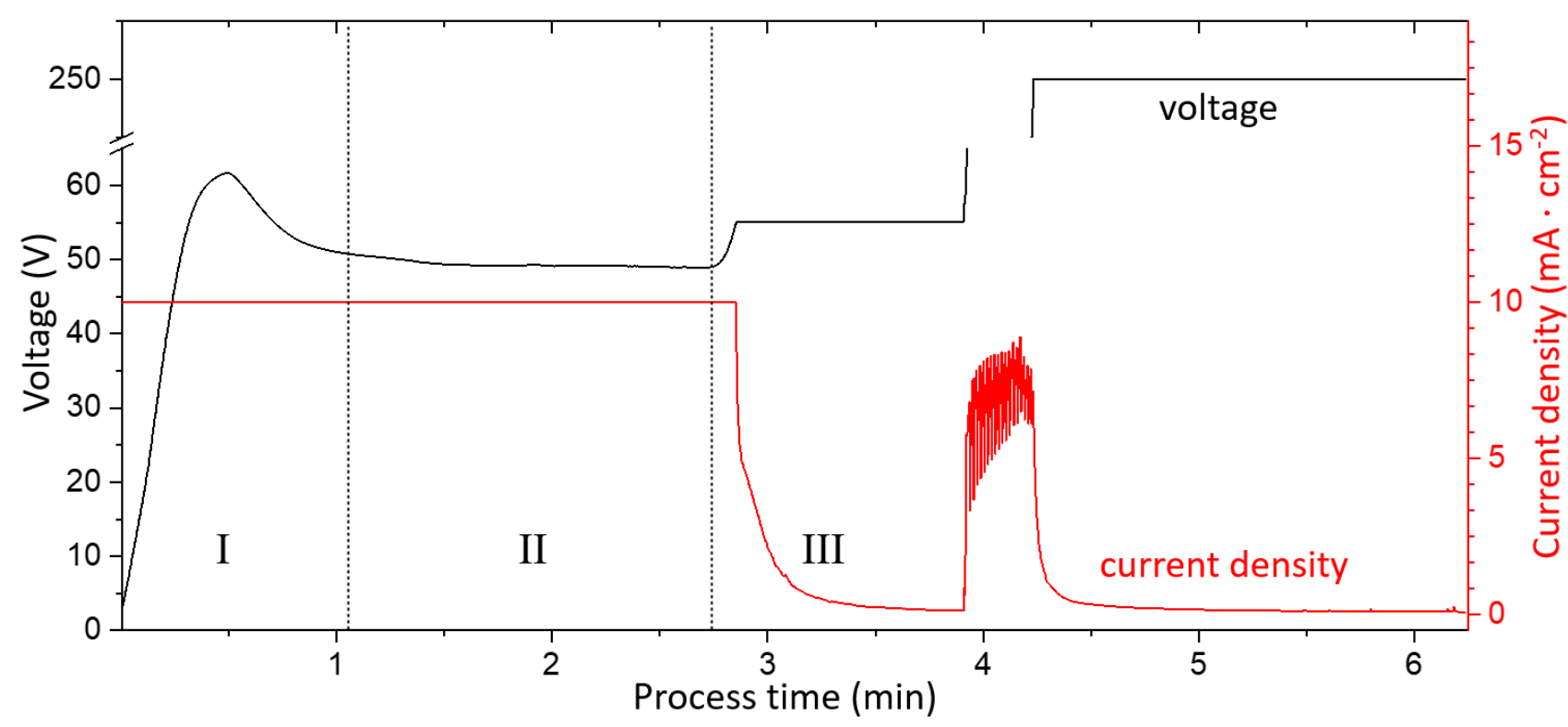

Figure 1 Voltage-time and current-time responses during anodizing followed by reanodizing an Al/Zr bilayer in $0.2 \mathrm{M}(\mathrm{COOH})_{2}$ electrolyte at room temperature

Table 1 Process parameters and morphological characteristics for anodizing and reanodizing $\mathrm{Al} / \mathrm{Zr}$ bilayer samples in oxalic and sulphuric acid solution employed in this study

\begin{tabular}{|c|c|c|c|c|c|c|}
\hline \multicolumn{2}{|c|}{$\begin{array}{c}\text { Electrolyte } \\
\text { concentration } \\
(\mathbf{M})\end{array}$} & $\begin{array}{c}\text { Current density } \\
\left(\mathbf{m A} \cdot \mathbf{c m}^{-2}\right)\end{array}$ & $\begin{array}{c}\text { Steady-state } \\
\text { voltage } \\
(\mathbf{V})\end{array}$ & $\begin{array}{c}\text { Reanodizing } \\
\text { voltage } \\
(\mathbf{V})\end{array}$ & $\begin{array}{c}\text { Sweep rate } \\
\left(\mathbf{V} \cdot \mathbf{s}^{-1}\right)\end{array}$ & $\begin{array}{c}\text { Population } \\
\text { density } \\
\text { per } \mathbf{c m}^{2}\end{array}$ \\
\hline \multirow{2}{*}{$(\mathrm{COOH})_{2}$} & 0.2 & 10 & 50 & 250 & 10 & $8.0 \cdot 10^{9}$ \\
\cline { 2 - 7 } & 0.6 & 10 & 40 & 250 & 10 & $1.3 \cdot 10^{10}$ \\
\hline \multirow{2}{*}{$\mathrm{H}_{2} \mathrm{SO}_{4}$} & 0.4 & 6 & 15 & 150 & 5 & $4.8 \cdot 10^{10}$ \\
\cline { 2 - 7 } & 2.0 & 6 & 9 & 50 & 2 & $1.7 \cdot 10^{11}$ \\
\hline
\end{tabular}

\subsection{Film morphology}

Figures 2, 3, and 4 show SEM images of surfaces and cross-fractures of the anodized and reanodized samples after selective dissolution of the overlaying PAA layer. On the anodized samples (Figure 2), ordered arrays of nanosized hillocks, presumably of $\mathrm{ZrO}_{2}$, are observed. The density and positioning of the hillocks is well correlated with the PAA cells for each type of electrolyte and the formation conditions. Likely, the hillocks grow under the PAA cells. From the tilted images, the hillocks are bell-shaped, have wide bases and relatively narrower tops. Notably, the bases of the hillocks are about twice the diameters of pores in the corresponding PAA films. This suggests that areas on $\mathrm{Zr}$ metal larger than the PAA pores are oxidized through the alumina barrier layer during the anodizing process. Another important feature is the dark gaps between the hillocks, presumably of crystalline zirconium oxide, which mimic the cellular grid of the PAA layer, with respect to formation voltage in each anodizing solution.

From Figure 3, the different film morphology is observed for the reanodized samples. Vertically aligned nanostructures, presumable of $\mathrm{ZrO}_{2}$, emerge from the film surface. Their lower parts are well separated from each other and localized within the areas that generally fit the size of the corresponding alumina cells. The black gaps separating the nanostructures are supposedly crystalline $\mathrm{ZrO}_{2}$. 

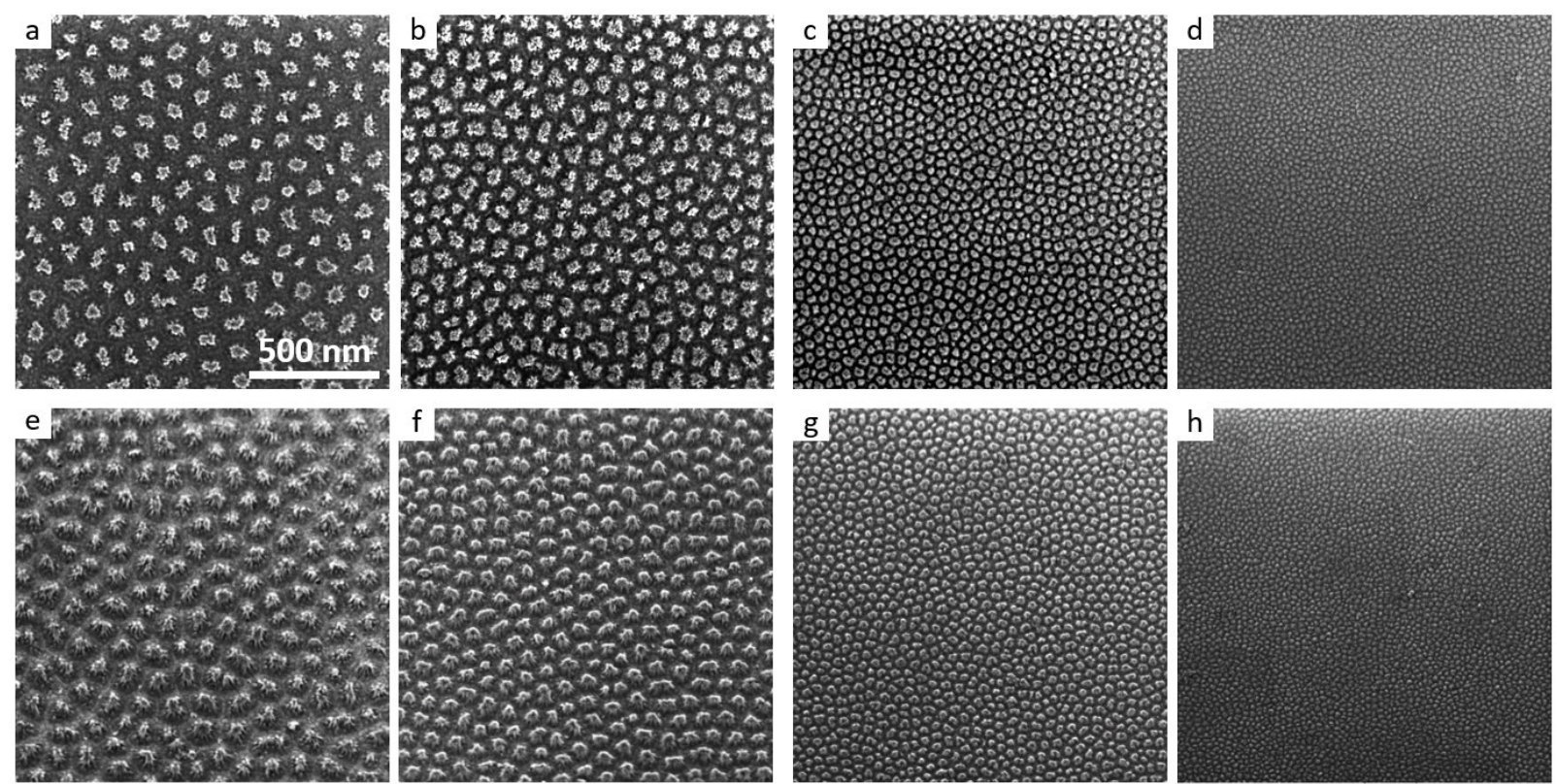

Figure 2 SEM top (upper row) and $30^{\circ}$ tilted (lower row) views of surfaces derived from an Al/Zr bilayer anodized in $0.2 \mathrm{M}(\mathrm{COOH})_{2}(\mathrm{a}, \mathrm{e}), 0.6 \mathrm{M}(\mathrm{COOH})_{2}(\mathrm{~b}, \mathrm{f}), 0.4 \mathrm{M} \mathrm{H}_{2} \mathrm{SO}_{4}(\mathrm{c}, \mathrm{g})$, and $2 \mathrm{M} \mathrm{H}_{2} \mathrm{SO}_{4}(\mathrm{~d}, \mathrm{~h})$ electrolytes.

Before observation the PAA overlayers were selectively dissolved. Scale bar is same for all images.
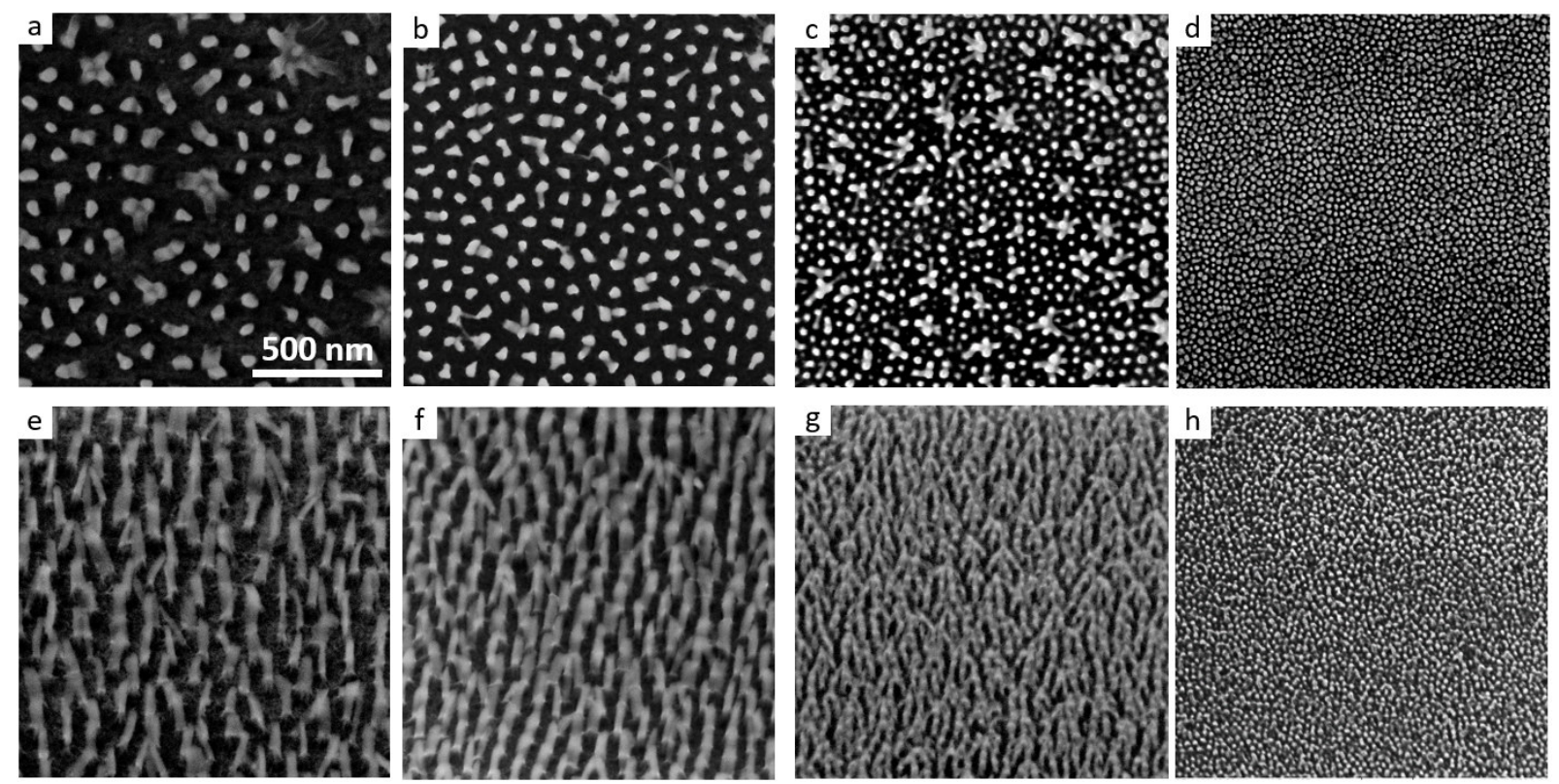

Figure 3 SEM top (upper row) and $30^{\circ}$ tilted (lower row) views of surfaces derived from an Al/Zr bilayer anodized and reanodized in $0.2 \mathrm{M}(\mathrm{COOH})_{2}(\mathrm{a}, \mathrm{e}), 0.6 \mathrm{M}(\mathrm{COOH})_{2}(\mathrm{~b}, \mathrm{f}), 0.4 \mathrm{M} \mathrm{H}_{2} \mathrm{SO}_{4}(\mathrm{c}, \mathrm{g})$, and $2 \mathrm{M} \mathrm{H}_{2} \mathrm{SO}_{4}$ $(d, h)$ electrolytes. Before observation the PAA overlayers were dissolved. Scale bar is same for all images.

From the tilted images (Figures $\mathbf{3} \mathbf{e}, \mathbf{f}, \mathbf{g}, \mathbf{h}$ ), it is seen that the $\mathrm{ZrO}_{2}$ nanostructures resemble rods, which are substantially longer than the hillocks grown in the anodized samples and rise well above the general film level. An important feature of the reanodized samples is that some tips of the nanorods tend to aggregate with their closest neighbors. These phenomena might be caused by a combination of two reasons. First, the nanostructures of such aspect ratio are the subject of strong van der Waals forces. Second, the bases of the nanorods might contain an amount of residual alumina mixed with zirconium oxide and partly dissolved during 
the PAA removal process, which results in mechanically weakening the bases. The latter might be resolved through further optimization of reanodizing conditions and will be studied in a future work.

Cross-section SEM images of the reanodized samples (Figure 4) allow to estimate the form and size of the $\mathrm{ZrO}_{2}$ nanostructures. The length and diameter of the rods vary depending on anodizing electrolyte. Further, the shape of the rods is not uniform along their length, and the diameters widen towards the substrate level, resembling the form of a tree trunk. It may be assumed that the hillocks are of the same sizes as the bottom parts of the rods and, therefore, might have similar chemical composition. This implies that the narrower, tall part of the rods is $\mathrm{ZrO}_{2}$ that forms by filing the pores in the PAA upper layer during the reanodizing process. From Figure 4, the nanorods seem to be well separated from the remaining $\mathrm{Zr}$ metal by a thin oxide layer, which is believed to be crystalline $\mathrm{ZrO}_{2}$.
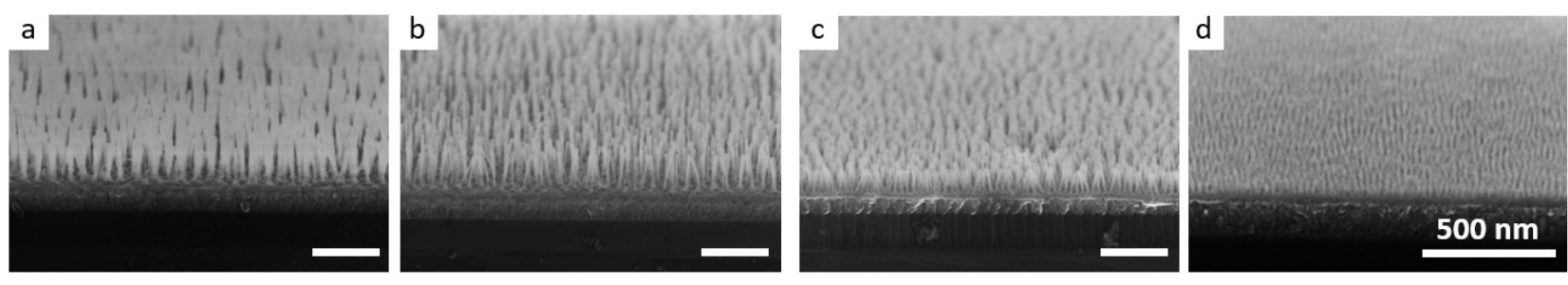

Figure 4 SEM views of cross-fractures of samples prepared by anodizing and reanodizing of $\mathrm{Al} / \mathrm{Zr}$ bilayer films in $0.2 \mathrm{M}(\mathrm{COOH})_{2}(\mathrm{a}), 0.6 \mathrm{M}(\mathrm{COOH})_{2}(\mathrm{~b}), 0.4 \mathrm{M} \mathrm{H}_{2} \mathrm{SO}_{4}(\mathrm{c})$, and $2 \mathrm{M} \mathrm{H}_{2} \mathrm{SO}_{4}$ (d) electrolytes. Before observation the PAA overlayers were dissolved away. Scale bar is $500 \mathrm{~nm}$ for all images.

The SEM results confirm that $\mathrm{ZrO}_{2}$ can grow through the alumina barrier layer and further within the pores of the upper PAA film, despite the commonly known fact that the oxide is only expected to grow in crystalline form underneath the alumina barrier layer [15]. This may be explained by suggesting that during the anodizing process amorphous $\mathrm{ZrO}_{2}$ grows towards the pore space by migration of $\mathrm{Zr}^{4+}$ through the alumina barrier layer and simultaneously mixing with alumina within the barrier layer. The $\mathrm{ZrO}_{2}$ hillocks thus formed inside the barrier layer can provide the pathway for further oxidation of $\mathrm{Zr}$ during the reanodizing. When reanodizing proceeds, the pores of the upper PAA layer are filled with growing $\mathrm{ZrO}_{2}$ material and form rod-like nanostructures. From such behavior, it is obvious that the transport number of $\mathrm{Zr}^{4+}$ cation through the oxide becomes significantly higher than 0.05 , the phenomenon to be investigated in more detail in future works.

\section{CONCLUSION}

Upright standing self-ordered arrays of $\mathrm{ZrO}_{2}$ nanostructures may be fabricated by anodization of $\mathrm{Al} / \mathrm{Zr}$ bilayered films in $(\mathrm{COOH})_{2}$ and $\mathrm{H}_{2} \mathrm{SO}_{4}$ electrolytes at various formation voltages. Generally, the process involves the conversion of Al metal into a PAA layer followed by oxidation of nether Zr layer. The growth of PAA-assisted hillock-like nanostructures of various sizes and geometries is achieved for the first time. The lengthening of $\mathrm{ZrO}_{2}$ nanostructures within the PAA pores appeared to be also possible due to the high-speed reanodizing technique. Substrate-supported self-ordered arrays of $\mathrm{ZrO}_{2}$ nanohillocks or nanorods are obtained after the dissolution of the PAA layer. The $\mathrm{ZrO}_{2}$ nanostructures thus grown are supposedly amorphous in their nature. Their formation is believed to be driven by an extraordinary increased outward migration of $\mathrm{Zr}^{4+}$ cations through the alumina barrier layer during the constant-current anodizing and high-speed reanodizing processes. This study contributes to understanding and utilizing the unusual ion migration and solid-state reactions during the PAA-assisted anodization of valve metals having basically low cation transport numbers.

\section{ACKNOWLEDGEMENTS}

The work was supported by a GACR grant no.17-13732S. Part of the work was carried out with the support of CEITEC Nano Research Infrastructure (MEYS CR, 2016-2019). 


\section{REFERENCES}

[1] ABRASHOV, A. A., GRIgORYAN, N. S., VAGRAMYAN, T. A., MESHALKIN, V. P., KOTEL'NIKOVA, A. V. and GRIBANOVA, A. A. Protective adhesive zirconium oxide coatings. Protection of Metals and Physical Chemistry of Surfaces. 2016. vol. 52, no. 7, pp. 1170-1174.

[2] MANJUNATHA, S., KRISHNA, R. H., THOMAS, T., PANIGRAHI, B. S. and DHARMAPRAKASH, M. S. MossBurstein effect in stable, cubic ZrO2: Eu+ 3 nanophosphors derived from rapid microwave-assisted solutioncombustion technique. Materials Research Bulletin. 2019. vol. 98, pp. 139-147.

[3] HAO, S. J., WANG, C., LIU, T. L., MAO, Z. M., MAO, Z. Q. and WANG, J. L. Fabrication of nanoscale yttria stabilized zirconia for solid oxide fuel cell. International Journal of Hydrogen Energy. 2017. vol. 42, no. 50, pp. 29949-29959.

[4] PICONI, C. and MACCAURO, G. Zirconia as a ceramic biomaterial. Biomaterials. 1999. vol. 20, no. 1, pp. 1-25.

[5] FIDELUS, J. D., ŁOJKOWSKI, W., MILLERS, D., GRIGORJEVA, L., SMITS, K. and PITICESCU, R. R. Zirconia based nanomaterials for oxygen sensors-generation, characterisation and optical properties. Solid State Phenomena. 2007. vol. 128, pp. 141-150.

[6] SUCIU, C., GAGEA, L., HOFFMANN, A. C. and MOCEAN, M. Sol-gel production of zirconia nanoparticles with a new organic precursor. Chemical engineering science. 2006. vol. 61, no. 24, pp. 1170-1174.

[7] BOTZAKAKI, M. A., XANTHOPOULOS, N., MAKARONA, E., TSAMIS, C., KENNOU, S., LADAS, S., GEORGA, S. N. and KRONTIRAS, C. A. ALD deposited ZrO2 ultrathin layers on Si and Ge substrates: A multiple technique characterization. Microelectronic Engineering. 201š. vol. 112, pp. 208-212.

[8] PARK, Y. J., HA, J. M., ALI, G., KIM, H. J., ADDAD, Y. and CHO, S. O Controlled fabrication of nanoporous oxide layers on zircaloy by anodization. Nanoscale research letters. 2015. vol. 10, no. 1, pp. 377.

[9] MOZALEV, A., SAKAIRI, M., SAEKI, I. and TAKAHASHI, H. Nucleation and growth of the nanostructured anodic oxides on tantalum and niobium under the porous alumina film. Electrochimica Acta. 2003. vol. 48, no. 20-22, pp. 3155-3170.

[10] MOZALEV, A., KHATKO, V., BITTENCOURT, C., HASSEL, A. W., GOROKH, G., LLOBET, E., and CORREIG, X. Nanostructured columnlike tungsten oxide film by anodizing AI/W/Ti layers on Si. Chemistry of materials. 2008. vol. 20, no. 20, pp. 6482-6493.

[11] MOZALEV, A., BENDOVA, M., GISPERT-GUIRADO, F. and LLOBET, E. Hafnium-Oxide 3-D Nanofilms via the Anodizing of Al/Hf Metal Layers. Chemistry of Materials. 2018. vol. 30, no. 8, pp. 2694-2708.

[12] SHIMIZU, K., KOBAYASHI, K., SKELDON, P., THOMPSON, G. E., and WOOD, G. C. Anodic oxidation of zirconium covered with a thin layer of aluminium. Thin Solid Films 1997. vol. 295, no. 1-2, pp. 156-161.

[13] DAVIES, J. A., DOMEIJ, B., PRINGLE, J. P. S. and BROWN, F. The migration of metal and oxygen during anodic film formation. Journal of the Electrochemical Society. 1965. vol. 112, no. 7, pp. 675-680.

[14] HABAZAKI, H., KOBAYASHI, K., TSUJI, E., ZHU, C., AOKI, Y., NAGATA, S., Highly increased capacitance and thermal stability of anodic oxide films on oxygen incorporated Zr-Ti alloy, J. Solid State Electrochem. 2017. vol. 21, pp. 2807-2816.

[15] THOMPSON, G. E., Porous anodic alumina: fabrication, characterization and applications, Thin Solid Films. 1997. Vol. 297, pp. 192-201. 